\title{
Characteristics of patients infected with Clostridioides difficile at a Saudi Tertiary Academic Medical Center and assessment of antibiotic duration
}

\author{
Khadijah M. Alammari and Abrar K. Thabit ${ }^{*}$ (1)
}

\begin{abstract}
Background: Clostridioides difficile infection (CDI) is a common hospital-associated diarrhea. Several antibiotics commonly associate with CDI; however, limited data are available on the duration of exposure prior to CDI. Moreover, studies on the characteristics of CDI patients in Saudi Arabia are limited. Therefore, this study aimed to characterize CDI patients identified over 10 years and assess antibiotic days of therapy (DOT) prior to CDI.

Methods: This was a retrospective descriptive analysis of CDI patients at a Saudi tertiary academic medical center between December 2007 and January 2018. Patients characteristics, prior exposure to known CDI risk factors, and DOT of antibiotics prior to CDI incidence were assessed.

Results: A total of 159 patients were included. Median age was 62 years. Most cases were hospital-acquired (71.1\%), non-severe (44.7\%), and admitted to medical wards (81.1\%). Prior exposure to antibiotics and acid suppression therapy were reported with the majority (76.1 and $75.5 \%$, respectively). The most frequently prescribed antibiotics were piperacillin/tazobactam, ceftriaxone, meropenem, and ciprofloxacin with median DOTs prior to CDI incidence of 14 days for the $\beta$-lactams and 26 days for ciprofloxacin. The distribution of DOT was significantly different for piperacillin/tazobactam in different units $(P=0.003)$ where its median DOT was the shortest in medical wards ( 11 days), and for ciprofloxacin among different severity groups $(P=0.013)$, where its median DOT was the shortest in severe CDI patients (11 days).
\end{abstract}

Conclusion: Most patients in this study had hospital-acquired non-severe CDI and were largely exposed to antibiotics and acid suppression therapy. Therefore, such therapies should be revised for necessity.

Keywords: Clostridioides difficile, Clostridium difficile, Antibiotics, Saudi arabia

\section{Background}

Clostridioides difficile infection (CDI) is the most common cause of hospital-associated diarrhea [1]. Generally, the acquisition of CDI is categorized based on the exposure to the healthcare system into hospital-onset

*Correspondence: akthabit@kau.edu.sa

Pharmacy Practice Department, Faculty of Pharmacy, King Abdulaziz University, 7027 Abdullah Al-Sulaiman Rd, Jeddah 22254-2265, Saudi Arabia
(HO-CDI), community-acquired (CA-CDI), and community-onset healthcare facility-associated (CO-HCFA) [1]. Some patients with a recurrent CDI episode who get exposed to the healthcare system were found to acquire a strain of CDI that is different from the index strain that caused the initial episode [2]. This finding adds to the evidence that one of the important modes of acquiring CDI is through hospitalization or exposure to healthcare by

c) The Author(s) 2021. This article is licensed under a Creative Commons Attribution 4.0 International License, which permits use, sharing, adaptation, distribution and reproduction in any medium or format, as long as you give appropriate credit to the original author(s) and the source, provide a link to the Creative Commons licence, and indicate if changes were made. The images or other third party material in this article are included in the article's Creative Commons licence, unless indicated otherwise in a credit line to the material. If material is not included in the article's Creative Commons licence and your intended use is not permitted by statutory regulation or exceeds the permitted use, you will need to obtain permission directly from the copyright holder. To view a copy of this licence, visit http://creativeco mmons.org/licenses/by/4.0/. The Creative Commons Public Domain Dedication waiver (http://creativecommons.org/publicdomain/ zero/1.0/) applies to the data made available in this article, unless otherwise stated in a credit line to the data. 
other means, such as regular hemodialysis or residence in nursing homes.

Certain risk factors are also known to be associated with CDI, such as exposure to antibiotics, older age, use of acid-suppressing agents, and use of antineoplastic agents $[3,4]$. Identifying these risk factors in admitted patients can help predicting the risk of acquiring the infection; hence, decreasing the exposure to modifiable factors, such as antibiotics and acid suppression therapy. Some antibiotics or classes of antibiotics are linked to CDI more than others. Penicillins, cephalosporines, carbapenems, fluroquinolones, and clindamycin are associated with CDI incidence that is folds higher than other antibiotics [4-7]. Time from antibiotic exposure to CDI development was reported in two previous studies. One evaluated CDI incidence while patients were still on therapy, whereas the other evaluated the incidence after antibiotic therapy cessation [4, 6]. The studies found an exposure of as short as a few days to as long as three months post therapy discontinuation was followed by CDI.

Data from Saudi Arabia on the characteristics of CDI patients are very limited. The majority of cases reported from three studies had HO-CDI followed by lower rates of CA-CDI and CO-HCFA [8-10]. Antibiotic exposure within three months was found with 26 of 42 cases (61\%) in one of the studies [8]. Other studies from the Middle East showed a similar prevalence pattern of CDI acquisition with antibiotic exposure (particularly fluoroquinolones, cephalosporins, and carbapenems) and proton pump inhibitors being the most reported factors predisposing CDI [11-15]. No additional CDI data from Saudi Arabia were found in the literature, as well as additional data on time to CDI incidence from antibiotic therapy initiation. Therefore, the objective of this study was to describe the characteristics of patients who acquired CDI that was confirmed by a laboratory test for $C$. difficile in a Saudi hospital. The study also aimed to define the duration of antibiotic exposure that preceded CDI incidence in these patients.

\section{Methods}

\section{Study design and patients}

This was a retrospective descriptive study on adult ( $\geq 18$ years old) CDI patients admitted to King Abdulaziz University Hospital, a tertiary academic medical center in Jeddah, Saudi Arabia. All patients presented to the hospital with CDI during the period from December 2007 to January 2018 were included. The characteristics of these patients, prior exposure to known CDI risk factors at the time of CDI incidence, and the duration of exposure to different antibiotics prior to CDI incidence (expressed as days of therapy, DOT) during or prior to the admission were assessed. Patients with inconsistent medication administration record data were excluded. The study was approved by the Research Committee of The Unit of Biomedical Ethics of Faculty of Medicine, King Abdulaziz University, Jeddah, Saudi Arabia.

\section{Definitions}

CDI was defined as positive toxin immunoassay in patients with diarrhea ( $\geq 3$ loose stools within one day). Acquisition forms of CDI were defined according to the Infectious Diseases Society of America (IDSA) and the United States Centers for Disease Control and Prevention (CDC) guidelines $[1,16]$. CA-CDI was defined as a CDI episode that occurs in a patient with no history of hospitalization within the previous 12 weeks and $48 \mathrm{~h}$ or less of hospitalization. HO-CDI was defined as CDI onset three days after admission (on or after day 4). If the symptoms started within 28 days after hospital discharge, the condition is termed CO-HCFA. CDI testing at our institution is done using IMMUNOQUICK Tox A/B (Biosynex, France), which has $88 \%$ sensitivity and $99 \%$ specificity [17]. According to the protocol of the microbiology laboratory at our institution, all formed stool samples are rejected; hence, only loose stool samples are accepted for CDI testing. Moreover, our hospital protocol mandates that stool specimens be transported to the microbiology laboratory as soon as possible within $1-2 \mathrm{~h}$ of collection to avoid potential degradation of $C$. difficile toxins. DOT was defined according to the CDC's National Healthcare Safety Network as the aggregate sum of days for which any amount of a specific antimicrobial agent was administered to individual patients as documented in the electronic medical record [18].

\section{Statistical analysis}

Data are presented using descriptive statistics as numbers, percentages, and median [interquartile range]. For the most used antibiotics, subgroup analyses using Mann-Whitney U test or Kruskal-Wallis test were carried out to determine the difference between the DOT of antibiotics in the subgroups. A $P$ value of $<0.05$ was considered significant. Statistical analysis was carried out using SPSS version 24.0 software (SPSS, Inc., Chicago, Illinois, USA).

\section{Results}

Of 167 identified patients with CDI, 159 were included as 8 patients had inconsistent antibiotic administration records. Characteristics of included patients are shown on Table 1. Most of the patients acquired CDI while in the hospital (71.1\%), and three-quarters had a prior antibiotic and acid suppression therapy exposure (76.1 and $75.5 \%$, respectively). Of $113 \mathrm{HO}$-CDI patients, 100 
Table 1 Patients characteristics

\begin{tabular}{|c|c|}
\hline Characteristic & $\mathrm{N}(\%)$ or Median [IQR] \\
\hline Age (years) & $62(48-71)$ \\
\hline Sex (male) & $80(50.3)$ \\
\hline \multicolumn{2}{|l|}{ Hospital unit } \\
\hline Medical & $129(81.1)$ \\
\hline ICU & $19(11.9)$ \\
\hline ED & $11(6.9)$ \\
\hline \multicolumn{2}{|l|}{ Acquisition } \\
\hline CA-CDI & $28(17.6)$ \\
\hline $\mathrm{HO}-\mathrm{CDI}$ & $113(71.1)$ \\
\hline CO-HCFA & $18(11.3)$ \\
\hline \multicolumn{2}{|l|}{ Severity } \\
\hline Non-severe & $71(44.7)$ \\
\hline Severe & $47(29.6)$ \\
\hline Severe complicated (fulminant) & $41(25.8)$ \\
\hline Time to CDI from admission, days ${ }^{\mathrm{a}}$ & $7(2-20)$ \\
\hline Non-CDI antibiotic therapy & $121(76.1)$ \\
\hline Number of antibiotics ${ }^{\mathrm{b}}$ & $3(1-5)$ \\
\hline Cancer chemotherapy & $22(13.8)$ \\
\hline Acid suppression therapy & $120(75.5)$ \\
\hline \multicolumn{2}{|l|}{ Type of acid suppression therapy ${ }^{c}$} \\
\hline Proton pump inhibitor & $47(29.6)$ \\
\hline $\mathrm{H}_{2}$-receptor antagonist & $2(1.3)$ \\
\hline Antacid & $1(0.6)$ \\
\hline$>1$ type & $70(44)$ \\
\hline Lower gastrointestinal disease & $14(8.8)$ \\
\hline
\end{tabular}

a In hospitalized patients, excluding patients presented to the ED

${ }^{b}$ In the subset of patients who received antibiotics

c In the subset of patients who received acid suppression therapy

$C A-C D /$ community-acquired $C$. difficile infection, $C D I C$. difficile infection, CO-HCFA community-onset healthcare facility-associated, DOT days of therapy, $E D$ emergency department, $H O-C D I$, hospital-onset $C$. difficile infection, ICU intensive care unit, IQR interquartile range

(88.5\%) were exposed to antibiotics prior to CDI incidence compared with 6 of 28 patients (21.4\%) and 15 of 18 patients $(83.3 \%)$ who developed CA-CDI and COHCFA CDI, respectively. A similar pattern was seen with the exposure to acid suppression therapy, where 95 (84.1\%), 9 (32.1\%), and 16 (88.9\%) of HO-CDI, CA-CDI, and CO-HCFA CDI patients, respectively, received a proton pump inhibitor or an $\mathrm{H}_{2}$-receptor antagonist. Only a few patients were on cancer chemotherapy or had a history of a lower gastrointestinal disease, such as inflammatory bowel disease or diverticulitis. The proportion of patients that developed non-severe CDI was the largest (44.7\%) followed by severe CDI (29.6\%) and severe complicated/fulminant (25.8\%).

Table 2 presents the frequency of use of antibiotics in a descending order with their median DOT. The
Table 2 Frequency of antibiotics and their days of therapy (DOT)

\begin{tabular}{lcl}
\hline Antibiotic & N (\%) & DOT (median [IQR]) \\
\hline All antibiotics & $159(100)$ & $17.5[12.25-26.5]$ \\
Piperacillin/tazobactam & $62(39)$ & $14[5.75-40.5]$ \\
Ceftriaxone & $60(37.7)$ & $14[5-43.25]$ \\
Meropenem & $59(37.1)$ & $14[7-26]$ \\
Ciprofloxacin & $50(31.4)$ & $26[8.75-56.5]$ \\
Cefuroxime & $37(23.3)$ & $14[7.5-44.5]$ \\
Gentamicin & $18(11.3)$ & $18[5.75-44]$ \\
Imipenem/cilastatin & $19(11.9)$ & $11[4-29]$ \\
Ceftazidime & $17(10.7)$ & $14[4.5-40]$ \\
Amoxicillin/clavulanic acid & $15(9.4)$ & $10[9-26]$ \\
Clarithromycin & $14(8.8)$ & $11.5[7.75-34.5]$ \\
Clindamycin & $14(8.8)$ & $27[9.75-58]$ \\
Trimethoprim/sulfamethoxazole & $12(7.5)$ & $9.5[4.25-62.25]$ \\
Cefazolin & $12(7.5)$ & $13[7.5-16.25]$ \\
Cloxacillin & $10(6.3)$ & $37[10.75-58.25]$ \\
Moxifloxacin & $9(5.7)$ & $38[10-61]$ \\
Azithromycin & $7(4.4)$ & $26[5-58]$ \\
Erythromycin & $7(4.4)$ & $47[3-56]$ \\
Rifampin & $5(3.1)$ & $7[5.5-36]$ \\
Amikacin & $4(2.5)$ & $35[10.75-54]$ \\
Ampicillin & $4(2.5)$ & $6[2-10.75]$ \\
Cefepime & $4(2.5)$ & $17.5[9-55.25]$ \\
Tigecycyline & $4(2.5)$ & $30[7-53.25]$ \\
Colistimethate sodium & $3(1.9)$ & $26[9-29]$ \\
Flucloxacillin & $2(1.3)$ & $17-30^{\mathrm{a}}$ \\
Ofloxacin & $2(1.3)$ & $38-49^{\mathrm{a}}$ \\
Doxycycline & $1(0.6)$ & 3 \\
Levofloxacin & $1(0.6)$ & 21 \\
\hline a Range & & \\
\hline
\end{tabular}

a Range

most frequently prescribed antibiotics were piperacillin/tazobactam, ceftriaxone, meropenem, and ciprofloxacin with median DOTs prior to CDI incidence of 14 days for the $\beta$-lactams and 26 days for ciprofloxacin.

In the subgroup analysis, the distribution of the four most commonly prescribed antibiotics largely followed the distribution of patients in the different categories as reported in Table 1. For example, since most of the patients during the study period were admitted to the medical ward, they represented the group that received most of the antibiotics. The DOT of these antibiotics appear in Fig. 1, where the distribution of DOT was significantly different for piperacillin/tazobactam in different units $(P=0.003)$. Counterintuitively, patients in non-intensive care unit (ICU) wards had the shortest antibiotic exposure to piperacillin/tazobactam prior to CDI development with a median DOT of 11 days. The distribution of DOT was also significant 

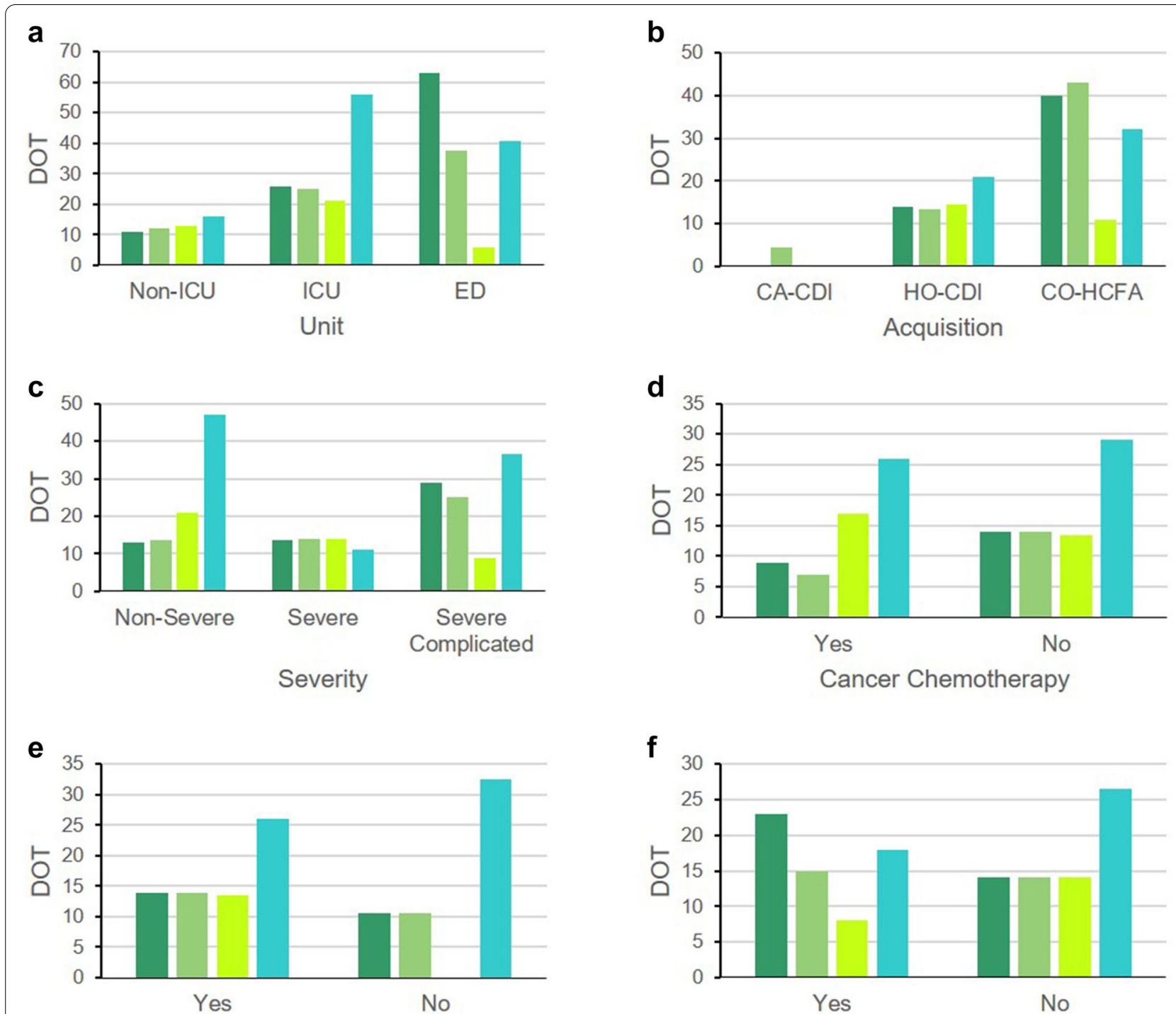

Acid Suppression Therapy

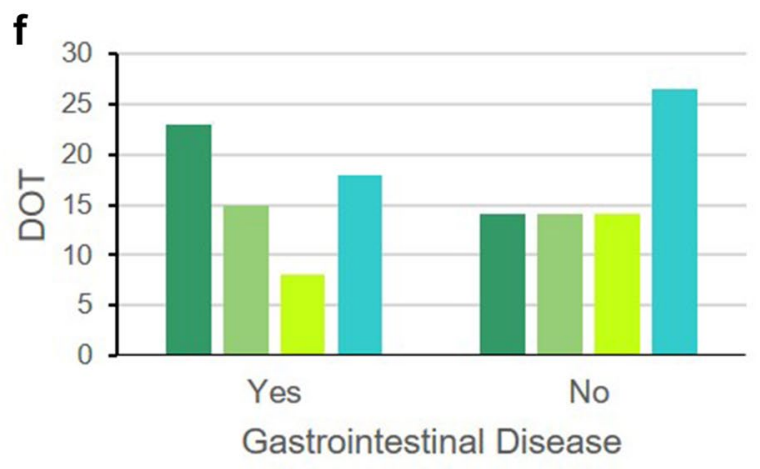

\section{Piperacillin/tazobactam = Ceftriaxone= Meropenem $=$ Ciprofloxacin}

Fig. 1 Median days of therapy of the four most used antibiotics in the subgroups. Significant difference was observed in the distribution of DOT of piperacillin/tazobactam $(P=0.003)$ between the hospital units, and of ciprofloxacin between severity groups $(P=0.013)$. CA-CDI, community-acquired C. difficile infection; CO-HCFA, community-onset healthcare facility-associated; DOT, days of therapy; ED, emergency department; $\mathrm{HO}-\mathrm{CDI}$, hospital-onset C. difficile infection; ICU, intensive care unit

for ciprofloxacin but among the different severity groups where the shortest median DOT was reported in the group of patients who exhibited severe CDI (11 days; $P=0.013$ ). Generally, in all other subgroups, shorter courses of meropenem preceded CDI compared with ciprofloxacin which were given for more days before CDI ensued as illustrated in Fig. 1; though, the differences were not statistically significant.

\section{Discussion}

$\mathrm{CDI}$ is the greatest reason for hospital-associated diarrhea [1]. In fact, the incidence of $C$. difficile colonization in the first days of hospitalization ranges from 16 to 
$20 \%$; however, it increases with longer hospital stay up to $45.4 \%[19,20]$. HO-CDI was consistently the major mode of CDI acquisition in our patient population despite a low overall incidence at our center where the cumulative 10 -year incidence in adults was $7 \%$ only [21]. The reporting of CO-HCFA CDI cases also indicate that recent hospitalization can amplify the risk of CDI acquisition. In fact, one study found that exposure to healthcare can be associated with colonization of different $C$. difficile strain in patients previously infected with the pathogen [2]. On the other hand, CA-CDI incidence in our population was much lower at $17.6 \%$ followed by CO-HCFA CDI at $11.3 \%$ only. The occurrence of CA-CDI was reported in low-risk populations, including those in younger age groups, those with no recent exposure to antibiotic, acid suppressants, asymptomatic carriers, contaminated food or water, and hypervirulent strains, as well as those with no recent outpatient visits and who are not in close proximity to farms [22]. However, the presence of any of these factors in non-hospitalized patients is also linked to CDI development as reported in a study by Chitnis et al. who found that $64.1 \%$ of patients with confirmed CA-CDI received antibiotics in a previous outpatient visit [23]. These findings were consistent with our patient population that developed CO-HCFA CDI, but not with CA-CDI patients, where the majority of the former were exposed to antibiotic, acid-suppression therapy, or both.

Patients who are 65 years or older can be at five- to tenfold higher risk for CDI, most likely with poor prognosis compared with younger patients $[3,5]$. In our study, half of the patient population were above 62 years. Thus, many were already at risk for CDI acquisition. Nonetheless, the presence of other risk factors may have augmented the risk. For instance, exposure to antibiotics and acid suppression therapy have been reported in about three-quarters of the patients in our study. The latter, especially proton pump inhibitors and $\mathrm{H}_{2}$-receptor antagonists, is significantly associated with CDI development [24], and most patients who received acid suppression therapy in the current study received more than one kind, such as a proton pump inhibitor or an $\mathrm{H}_{2}$-receptor antagonist. Conversely, cancer chemotherapy was reported in a small fraction of patients (13.8\%). This can be possibly attributed to the fact that our center is not an oncology specialized center. Nevertheless, if that was the case, more CDI patients would have been included since cancer chemotherapy is another known risk factor for CDI $[4,25]$. Similarly, lower gastrointestinal diseases, particularly inflammatory bowel disease, can put patients at risk for CDI [26]. However, this was also reported in a small number of patients in this study (9.3\%). Of all these CDI risk factors, studies from Saudi Arabia identified antibiotics and proton pump inhibitors as the major risk factors that were significantly associated with CDI development, which were the two most prevalent factors in our patient population $[10,27,28]$.

It was not surprising that many CDI patients in our study were exposed to antibiotics, where a median of three antibiotics were used (collectively, but not necessarily concurrently) at a median total DOT of 17.5 days. Notably, the most frequently prescribed antibiotics in our study belong to culprit antibiotic classes, $\beta$-lactams and fluoroquinolones. Similar finding was reported in another study from Saudi Arabia that evaluated antibiotics use, where cephalosporins and fluoroquinolones were the most used antibiotics [8]. The prescribing pattern of antibiotics in Saudi Arabia included $\beta$-lactams, fluoroquinolones, and macrolides on top of the list $[29,30]$. A similar pattern was reported in studies from other countries, such as Canada, Italy, India, Jordan, and Turkey [31-36]. However, a study from the United States showed a slight decrease in the rate of prescription of antipseudomonal $\beta$-lactams (except carbapenems which showed an increase) and fluoroquinolones in favor of narrowspectrum $\beta$-lactams [37]. In our study, piperacillin/tazobactam and meropenem were most likely prescribed for empiric purposes. Both, as well as ceftriaxone and ciprofloxacin, were significantly associated with CDI in several previous studies. Results from two meta-analyses showed that $\beta$-lactams (of all classes), fluoroquinolones, and clindamycin were the antibiotics with the highest likelihood to increase risk of CDI $[38,39]$. However, it is important to realize that the exposure to antibiotics alone may not be a factor, but also the duration of that exposure, as well. A short DOT to CDI was reported in a previous study, where an exposure of 6 days to cefazolin in 80 patients and of 8 days to cefepime in 186 patients preceded CDI [4]. Our study revealed that patients developed CDI after an antibiotic exposure of approximately 7 days. A study by Hengens et al. found that the probability of CDI incidence remains up to three months after the last dose of antibiotic [6].

As CDI incidence in Saudi Arabia was reported low from many institutions, especially from the community, it is presumed to have a slight impact on the healthcare system and the economy compared with the status in other countries where CDI incidence is high $[9,10,21]$. However, since CDI was mostly acquired in the hospital setting and given the predictability of its incidence based on the high prevalent risk factors of antibiotics and acid suppression therapy use, we hold that rapid discharge of stable patients to reduce hospital length of stay, appropriate antibiotic stewardship, and careful evaluation of the need for acid suppression therapy can further help limiting the development of CDI in vulnerable patients. 
Our study has several strengths. It is one of very few studies to characterize the CDI population in Saudi Arabia, measures the prevalence of different ways CDI is contracted, and identifies the prevalence of known CDI risk factors. Additionally, the study spanned a period of 10 years and included detailed antibiotic utilization data. Nevertheless, the study was limited by a few factors. It was single-centered, which may limit the ability to generalize its results to other centers in Saudi Arabia. Also, there were some inconsistencies in the medication administration records of some patients that resulted in their exclusion. Moreover, patients who may have been hospitalized or undergone medical procedures in other facilities may not have been identified since such factors may increase the risk for $C$. difficile colonization. While a history of a lower gastrointestinal disease was recorded, history of gastrointestinal surgeries was not captured. Additionally, the only test utilized at our institution for $C$. difficile detection is toxin immunoassay with a reported sensitivity of $88 \%$. This indicates that without the utilization of glutamate dehydrogenase test for initial screening or a second verification test (such as polymerase chain reaction or culture), roughly $12 \%$ of the tested population may have been missed and not included in the study due to false negative results.

\section{Conclusion}

CDI is a common hospital-acquired infection. Many CDI patients in this study acquired it from the hospital setting in a non-severe form and were largely exposed to antibiotics and acid suppression therapy. Therefore, hospitalized patients should be assessed for the necessity of such therapies and discontinue them when deemed unnecessary after evaluating the overall clinical status before CDI may ensue.

\begin{abstract}
Abbreviations
CA-CDI: Community-acquired Clostridioides difficile infection; CDC: Centers for Disease Control and Prevention; CDI: Clostridioides difficile Infection; CO-HCFA: Community-onset healthcare facility-associated Clostridioides difficile infection; DOT: Days of therapy; ED: Emergency department; HO-CDI: Hospital-onset Clostridioides difficile infection; ICU: Intensive care unit; IDSA: Infectious Diseases Society of America.
\end{abstract}

\section{Acknowledgements}

We thank Dr. Alaa Babonji and Dr. Mohammed Hussain for helping with some data collection. We also thank Mr. Joel Kurtzhalts, jr. for his help with language editing.

\section{Authors' contributions}

KA carried out the data collection and participated in manuscript writing. AT designed the study, performed data analysis and interpretation, and participated and revised the final manuscript. Both authors read and approved the final manuscript.
Funding

Not applicable.

Availability of data and materials

Data are available upon request from the authors.

Ethics approval and consent to participate

The study was approved by the Research Committee of The Unit of Biomedical Ethics of Faculty of Medicine, King Abdulaziz University, Jeddah, Saudi Arabia (reference 123-18).

\section{Consent for publication}

Not applicable.

\section{Competing interests}

None.

Received: 30 October 2020 Accepted: 10 February 2021

Published online: 17 February 2021

\section{References}

1. McDonald LC, Gerding DN, Johnson S, Bakken JS, Carroll KC, Coffin SE, et al. Clinical practice guidelines for Clostridium difficile infection in adults and children: 2017 update by the infectious diseases Society of America (IDSA) and Society for Healthcare Epidemiology of America (SHEA). Clin Infect Dis. 2018;66(7):987-94. https://doi.org/10.1093/cid/ciy149.

2. Thabit AK, Housman ST, Burnham CD, Nicolau DP. Association of healthcare exposure with acquisition of different Clostridium difficile strain types in patients with recurrent infection or colonization after clinical resolution of initial infection. J Hosp Infect. 2016;92(2):167-72. https://doi. org/10.1016/j.jhin.2015.11.009.

3. Czepiel J, Drozdz M, Pituch H, Kuijper EJ, Perucki W, Mielimonka A, et al. Clostridium difficile infection: review. Eur J Clin Microbiol Infect Dis. 2019;38(7):1211-21. https://doi.org/10.1007/s10096-019-03539-6.

4. Thabit AK, Varugehese CA, Levine AR. Antibiotic use and duration in association with Clostridioides difficile infection in a tertiary academic medical center: a retrospective case-control study. Anaerobe. 2019;59:126-30. https://doi.org/10.1016/j.anaerobe.2019.06.016.

5. Leffler DA, Lamont JT. Clostridium difficile infection. N Engl J Med. 2015;372(16):1539-48. https://doi.org/10.1056/NEJMra1403772.

6. Hensgens MP, Goorhuis A, Dekkers OM, Kuijper EJ. Time interval of increased risk for Clostridium difficile infection after exposure to antibiotics. J Antimicrob Chemother. 2012;67(3):742-8. https://doi.org/10.1093/ $\mathrm{jac} / \mathrm{dkr} 508$.

7. Johnson S, Samore MH, Farrow KA, Killgore GE, Tenover FC, Lyras D, et al. Epidemics of diarrhea caused by a clindamycin-resistant strain of Clostridium difficile in four hospitals. N Engl J Med. 1999;341(22):1645-51. https://doi.org/10.1056/nejm199911253412203.

8. Al-Tawfiq JA, Abed MS. Clostridium difficile-associated disease among patients in Dhahran, Saudi Arabia. Travel medicine and infectious disease. 2010;8(6):373-6. https://doi.org/10.1016/j.tmaid.2010.10.003.

9. Al-Tawfiq JA, Rabaan AA, Bazzi AM, Raza S, Noureen M. Clostridioides (Clostridium) difficile-associated disease: epidemiology among patients in a general hospital in Saudi Arabia. Am J Infect Control. 2020. https://doi. org/10.1016/j.ajic.2020.01.011.

10. Alzouby S, Baig K, Alrabiah F, Shibl A, Al-Nakhli D, Senok AC. Clostridioides difficile infection: Incidence and risk factors in a tertiary care facility in Riyadh. Saudi Arabia J Infect Public Health. 2020;13(7):1012-7. https://doi. org/10.1016/j.jiph.2019.10.014.

11. Malekzadegan Y, Halaji M, Hasannejad-Bibalan M, Jalalifar S, Fathi J, Ebrahim-Saraie HS. Burden of Clostridium (Clostridioides) difficile infection among patients in Western Asia: a systematic review and meta-analysis. Iran J Public Health. 2019;48(9):1589-99.

12. Al Assaad R, Dakessian A, Bachir R, Bizri AR, El Sayed M. Significance of Clostridium difficile in community-acquired diarrhea in a tertiary care center in Lebanon. Sci Rep. 2020;10(1):5678. https://doi.org/10.1038/ s41598-020-62418-9.

13. Karaoui WR, Rustam LBO, Bou Daher H, Rimmani HH, Rasheed SS, Matar GM, et al. Incidence, outcome, and risk factors for recurrence of 
nosocomial Clostridioides difficile infection in adults: a prospective cohort study. J Infect Public Health. 2020;13(4):485-90. https://doi.org/10.1016/j. jiph.2019.11.005.

14. Azimirad M, Krutova M, Yadegar A, Shahrokh S, Olfatifar M, Aghdaei HA, et al. Clostridioides difficile ribotypes 001 and 126 were predominant in Tehran healthcare settings from 2004 to 2018: a 14-year-long crosssectional study. Emerg Microbes Infect. 2020;9(1):1432-43. https://doi. org/10.1080/22221751.2020.1780949.

15. Jamal WY, Rotimi VO. Surveillance of antibiotic resistance among hospital- and community-acquired toxigenic Clostridium difficile Isolates over 5-year period in Kuwait. PLoS ONE. 2016;11(8):e0161411. https://doi. org/10.1371/journal.pone.0161411.

16. National Healthcare Safety Network. Multidrug-Resistant Organism and Clostridioides difficile Infection (MDRO/CDI) Module. Centers for Disease Control and Prevention, Atlanta, GA. 2021. https://www.cdc.gov/nhsn/ pdfs/pscmanual/12pscmdro_cdadcurrent.pdf.

17. Biosynex Group. IMMUNOQUICK ${ }^{\circledR}$ : Clostridium difficile GDH and Tox A/B product catalog. Strasbourg Cedex, France. 2015

18. Centers for Disease Control and Prevention. Antimicrobial Use and Resistance (AUR) Module. Atlanta, GA. 2020

19. Hung YP, Lin HJ, Wu TC, Liu HC, Lee JC, Lee Cl, et al. Risk factors of fecal toxigenic or non-toxigenic Clostridium difficile colonization: impact of Tolllike receptor polymorphisms and prior antibiotic exposure. PLOS ONE. 2013;8(7):e69577. https://doi.org/10.1371/journal.pone.0069577.

20. Marciniak C, Chen D, Stein AC, Semik PE. Prevalence of Clostridium difficile colonization at admission to rehabilitation. Arch Phys Med Rehabil. 2006;87(8):1086-90. https://doi.org/10.1016/j.apmr.2006.03.020.

21. Aljafel NA, Al-Shaikhy HH, Alnahdi MA, Thabit AK. Incidence of Clostridioides difficile infection at a Saudi Tertiary Academic Medical Center and compliance with IDSA/SHEA, ACG, and ESCMID guidelines for treatment over a 10-year period. J Infect Public Health. 2020. https://doi. org/10.1016/j.jiph.2020.03.007

22. Ofori E, Ramai D, Dhawan M, Mustafa F, Gasperino J, Reddy M. Community-acquired Clostridium difficile: epidemiology, ribotype, risk factors, hospital and intensive care unit outcomes, and current and emerging therapies. J Hosp Infect. 2018;99(4):436-42. https://doi.org/10.1016/j. jhin.2018.01.015.

23. Chitnis AS, Holzbauer SM, Belflower RM, Winston LG, Bamberg WM, Lyons C, et al. Epidemiology of community-associated Clostridium difficile infection, 2009 through 2011. JAMA internal medicine. 2013;173(14):1359-67. https://doi.org/10.1001/jamainternmed.2013.7056.

24. Dial S, Delaney JA, Barkun AN, Suissa S. Use of gastric acid-suppressive agents and the risk of community-acquired Clostridium difficile-associated disease. JAMA. 2005;294(23):2989-95. https://doi.org/10.1001/ jama.294.23.2989

25. Blot E, Escande MC, Besson D, Barbut F, Granpeix C, Asselain B, et al. Outbreak of Clostridium difficile-related diarrhoea in an adult oncology unit: risk factors and microbiological characteristics. J Hosp Infect. 2003;53(3):187-92.

26. Ananthakrishnan AN, Issa M, Binion DG. Clostridium difficile and inflammatory bowel disease. Med Clin North Am. 2010;94(1):135-53. https://doi. org/10.1016/j.mcna.2009.08.013.

27. Alalawi M, Aljahdali S, Alharbi B, Fagih L, Fatani R, Aljuhani O. Clostridium difficile infection in an academic medical center in Saudi Arabia: prevalence and risk factors. Ann Saudi Med. 2020;40(4):305-9. https://doi. org/10.5144/0256-4947.2020.305.

28. Al Otaibi H, Ahmed AE, Alammari M. Association between omeprazole use and Clostridium difficile infection among hospitalized patients: A case-control study of the Saudi population. Qatar Med J. 2017;2017(2):2. https://doi.org/10.5339/qmj.2017.2.

29. Alanazi MQ, Salam M, Alqahtani FY, Ahmed AE, Alenaze AQ, Al-Jeraisy M, et al. An evaluation of antibiotics prescribing patterns in the Emergency Department of a Tertiary Care Hospital in Saudi Arabia. Infect Drug Resist. 2019;12:3241-7. https://doi.org/10.2147/IDR.S211673.

30. Al-Tawfiq JA, Momattin H, Hinedi K. Empiric antibiotic therapy in the treatment of community-acquired pneumonia in a General Hospital in Saudi Arabia. J Glob Infect Dis. 2019;11 (2):69-72. https://doi.org/10.4103/ jgid.jgid_84_18.

31 Yu J, Wang G, Davidson A, Chow I, Chiu A. Antibiotics utilization for community acquired pneumonia in a Community Hospital Emergency Department. J Pharm Pract. 2020. https://doi.org/10.1177/0897190020 953032.

32. Orlando V, Monetti VM, Moreno Juste A, Russo V, Mucherino S, Trama $\mathrm{U}$, et al. Drug utilization pattern of antibiotics: the role of age, sex and municipalities in determining variation. Risk ManagHealthc Policy. 2020;13:63-71. https://doi.org/10.2147/RMHP.S223042.

33. Patra SK, Mishra SB, Rath A, Samal S, Iqbal SN. Study of antimicrobial utilization and cost of therapy in medicine intensive care unit of a tertiary care hospital in Eastern India. Indian J Crit Care Med. 2020;24(10):938-42. https://doi.org/10.5005/jp-journals-10071-23552.

34. Trikha S, Dalpath SK, Sharma M, Shafiq N. Antibiotic prescribing patterns and knowledge of antibiotic resistance amongst the doctors working at public health facilities of a state in northern India: a cross sectional study. J Family Med Prim Care. 2020;9(8):3937-43. https://doi.org/10.4103/ffmpc jfmpc_367_20.

35. Jarab AS, Mukattash TL, Nusairat B, Shawaqfeh M, Farha RA. Patterns of antibiotic use and administration in hospitalized patients in Jordan. Saudi Pharm J. 2018;26(6):764-70. https://doi.org/10.1016/j.jsps.2018.04.009.

36. Akdemlr Kalkan I, Cinar G, Pehllvanli A, Urkmez F, TopaloGlu IE, Akyol B, et al. Pattern of systemic antibiotic use and potential drug interactions: evaluations through a point prevalence study in Ankara University Hospitals. Turk J Med Sci. 2020. https://doi.org/10.3906/sag-2004-164.

37. Thabit AK, Shea KM, Guzman OE, Garey KW. Antibiotic utilization within 18 community hospitals in the United States: A 5-year analysis. Pharmacoepidemiol Drug Saf. 2020. https://doi.org/10.1002/pds.5156.

38. Brown KA, Khanafer N, Daneman N, Fisman DN. Meta-analysis of antibiotics and the risk of community-associated Clostridium difficile infection. Antimicrob Agents Chemother. 2013;57(5):2326-32. https://doi. org/10.1128/AAC.02176-12.

39. Deshpande A, Pasupuleti V, Thota P, Pant C, Rolston DD, Sferra TJ, et al. Community-associated Clostridium difficile infection and antibiotics: a meta-analysis. J Antimicrob Chemother. 2013;68(9):1951-61. https://doi. org/10.1093/jac/dkt129.

\section{Publisher's Note}

Springer Nature remains neutral with regard to jurisdictional claims in published maps and institutional affiliations.

\footnotetext{
Ready to submit your research? Choose BMC and benefit from:

- fast, convenient online submission

- thorough peer review by experienced researchers in your field

- rapid publication on acceptance

- support for research data, including large and complex data types

- gold Open Access which fosters wider collaboration and increased citations

- maximum visibility for your research: over 100M website views per year
}

At BMC, research is always in progress.

Learn more biomedcentral.com/submissions 